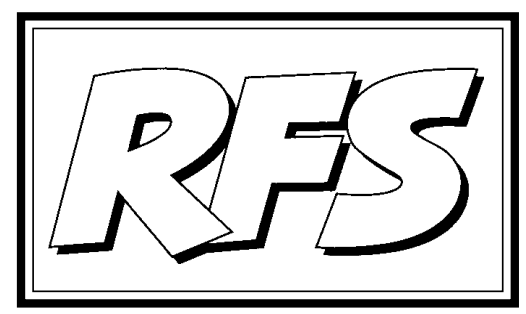

Revista de Fomento Social, 56 (2001), 671-678

\title{
Inmigración y Derechos humanos ${ }^{1}$
}

\author{
Paul VALADIER, $\mathbf{S J}^{2}$
}

El objeto de esta conferencia es proponer una reflexión crítica a propósito del derecho a la inmigración. No se trata, pues, de tratar del derecho de asilo, reconocido por el derecho internacional y bien fundado desde el punto de vista de los Derechos humanos, incluso si el efectivo respeto de un derecho como ése deja, realmente, mucho que desear. No me referiré tampoco a la inmigración económica cuando viene justificada, en un determinado país, por condiciones como las hambrunas, la miseria o una situación catastrófica como la sequía. Me referiré, más bien del derecho a la inmigración fundado en el trabajo, derecho reivindicado a la vez por los Estados para acoger a ciertas categorías de trabajadores, y por los que reclaman este derecho en nombre de sus propias competencias profesionales (científicas de alto nivel,

1 Versión del original francés inédito de José Mạ Margenat SJ .

2 Profesor de Filosofía Política y de Ética. Centre Sèvres. París. Ponencia presentada en la reunión del grupo EUROJESS 2001. Véase crónica de dicha reunión en este mismo número. 
investigadores diversos o, en el otro extremo de la escala, trabajadores que aportan su fuerza de trabajo físico). Nos preguntaremos en la primera parte en qué puede encontrar fundamento y justificación un derecho de este tipo en los Derechos humanos, y propondremos en un segundo momento algunos elementos de reflexión crítica.

\section{La fundamentación de la inmigración en los Derechos humanos}

Tres razones pueden ser invocadas para fundar en los Derechos humanos la inmigración.

1) La Carta de la ONU de 1948 reconoce en su artículo 13.2 que toda persona tiene el derecho a salir de cualquier país, incluso del propio, y a regresar a su país. Incluso si ese texto es limitativo, ya que precisa en el parágrafo anterior que esta libertad se ejerce en el interior de un Estado, es decir teniendo en cuenta su legislación, se afirmará que este derecho de circulación, aún con la limitación indicada, debe ser ampliado. La extensión de este derecho partirá del principio fundamental incluido en la misma noción de Derechos humanos. Se explicará así que pertenece a todo hombre, por naturaleza y por derecho, la libertad de circulación y de desplazamiento. Se dirá incluso que se trata en este caso de una reivindicación fundamental. A partir de ahí, ¿por qué no extender este derecho y entenderlo como un derecho a desplazarse para proponer su fuerza de trabajo, en cualquier lugar en que haya demanda, o incluso en los lugares en que tal fuerza de trabajo es solicitada por empresas o por Estados que permiten o favorecen un desplazamiento tal? De esta forma la inmigración por motivo de trabajo se convierte en una simple extensión de un derecho ya reconocido. Un tal derecho se limita entonces a levantar acta del derecho fundamental de todo hombre a desplazarse allá donde le parezca bien, sin tener que dar cuenta a nadie sobre ello, y aún menos a ser retenido en su país por una legislación limitativa.

2) Podríamos añadir que un derecho de esta naturaleza es sin embargo nuevo. Éste, en efecto, no surge de ninguna manera de ese derecho a tener derechos que, según Hannah Arendt, constituye la matriz de las Cartas, ya que esta fórmula presupone un sujeto "desnudo" que reivindica ante la humanidad, y justamente en nombre de esta misma humanidad, ser reconocido como hombre a fin de poder ejercer derechos 
elementales. Tendríamos que decir más bien que el fenómeno reciente dela globalización ${ }^{3}$ ha transformado las relaciones de trabajo y convertido en posible, casi necesario, el ejercicio de un derecho a hacer valer sus talentos 0 a ofrecerlos en el mercado de trabajo allá donde eso sea posible y necesario. Ninguna limitación nacional o estatal sería legítima si impidiera el ejercicio de un derecho como éste. La reivindicación de ese derecho se basa en la globalización por una parte y en la 'superación' de los Estados nacionales por otra. En relación con el argumento precedente se desarrolla un derecho nuevo apoyándose en el estado mundial de la economía y de las posibilidades que ésta ofrece para descubrir nuevos derechos, coherentes con esta situación. Existe una novedad, que está legitimada por el estado histórico de la economía y de las relaciones internacionales.

3) A partir de la base de tal 'superación' de los Estados-nación y de sus exigentes legislaciones, se avanzará en otra legitimación. Este derecho a la inmigración, se añade, no significa otra cosa que una conquista suplementaria del individualismo moderno, puesto que se orienta en el sentido de la desvinculación o emancipación del individuo en relación con sus vínculos y compromisos tradicionales. Si toda la modernidad representa el lento ascenso hacia el individualismo y la convergencia hacia la ampliación de los derechos del individuo; si, para decirlo de otro modo, esta modernidad coincide con la afirmación cada vez más grande de la autonomía del individuo, está claro que este derecho no hace más que prolongar un proceso comenzado hace tiempo, en la línea recta de la modernidad emancipadora del individuo con respecto a los vínculos de tradición, en este caso nacional y estatal. Tener el derecho de inmigrar para proponer la propia fuerza de trabajo, libremente y sin sentirse vinculado por una nacionalidad o una tradición cultural, es un paso adelante en la instauración de un cosmopolitismo, que ya ha sido anunciado por algunos teóricos como elemento constitutivo del mundo moderno. Se trata aquí de un cosmopolitismo económico, pero que coincide plenamente con el proyecto mismo de una sociedad cada vez más emancipada de los vínculos tradicionales. Nace así un derecho del individuo libre en un mundo él también libre y abierto a la libertad de cada uno y de todos.

3 Globalisation en el original. 
Esos tres argumentos se sostienen mutuamente. El derecho a circular ya reconocido por nuestras Cartas ha de ser de alguna forma ampliado; un nuevo derecho se impone en la lógica de los Derechos humanos y de la modernidad emancipadora; esto está en coherencia con una situación histórica original, propicia al desarrollo de nuevos derechos que hasta ahora han sido ignorados o limitados por los Estados, hoy por hoy superados.

\section{Interrogantes sobre un derecho de este tipo como derecho del hombre}

Podemos, sin embargo, plantearnos algunas preguntas y formular algunas críticas a la articulación que acabo de exponer entre Derechos humanos e inmigración.

1) Un reproche esencial que se puede hacer a estos argumentos consiste en subrayar hasta qué punto se inscriben en una línea estrictamente individualista de los Derechos humanos. Si se consideran las cosas desde el ángulo del trabajador que va a emigrar, es forzoso constatar que por su salida él abandona su país yéndose a ofrecer su fuerza de trabajo al servicio de otro. Ahora bien, su competencia profesional ha sido adquirida no sin esfuerzo en su país de origen, y esta inversión, cuando se trata de científicos de alto nivel, de ingenieros o de médicos, puede haber gravado mucho el presupuesto nacional. El inmigrante, al marcharse, se lleva con él no sólo su fuerza de trabajo, sino algo de la riqueza y del patrimonio nacional; despoja así al país de un capital que puede ser importante. Es más, las inversiones realizadas para él, en otro tiempo, podrían haber sido útiles para otros servicios o para ayudar a categorías de población necesitadas. Bajo la justificación de derecho a la inmigración, se hace alarde de un individualismo muy parecido a una forma de egoísmo y de indiferencia al bien común. No sólo el inmigrado ha costado a la comunidad nacional, sino que éste rehusa devolverle los servicios que aquella está legítimamente esperando de él.

Conviene añadir que el discurso de la 'superación' de los Estados nacionales tiene algo de hipócrita. Pues un individuo realmente autónomo, en el sentido moderno de la palabra, debe tener el sentido de sus responsabilidades en relación con los otros, y no sólo la preocupación por sus intereses. Debería, por ello, admitir la deuda hacia su propia nación y su Estado, más que hablar tan desconsideradamente de 
'superación', en su caso porque le resultaútil parajustificar la indiferencia al bien común. Conviene, pues, no confundir individualismo egoísta con autonomía correctamente comprendida, que implica el sentido de la solidaridad con los otros, mientras que aquél no considera más los intereses propios de cada uno. La argumentación precedente peca de ocultar los vínculos sociales y económicos con el país de origen en nombre de un individualismo más cercano al egoísmo que a la autonomía correctamente entendida.

2) Los efectos de una inmigración de fuerza de trabajo formada y mantenida por el país de origen serán, sin duda, perceptibles. Lo más evidente resulta el empobrecimiento de la riqueza nacional y la pérdida de capitales humanos que hubiesen permitido el desarrollo del país. Este efecto puede, evidentemente, variar en sus consecuencias según la situación económica del país y su gravedad será más o menos grande. Pero, en todo caso, la fuga de cerebros se traduce en un debilitamiento del sistema de salud, de la producción económica, de la renovación de la investigación científica y técnica, dela influencia delas universidades y centros de investigación. Una fuga así puede ser muy grave en el caso de un país pobre, pero plantea también problemas en cualquier hipótesis, incluso en países bien provistos en riquezas humanas. El país pobre del que se emigra quedará expuesto a una miseria más grande, y aún así con la justificación del derecho del individuo serán los pobres los que pagarán el peso de esta 'libertad nueva'. Hemos de preguntarnos, por tanto, si es legítimo hablar de Derechos humanos, ya que su traducción social conlleva el empobrecimiento de la colectividad nacional y el incremento de la pobreza, incluso de la miseria para los menos protegidos. Empobrecimiento que por carambola se vuelve contra los derechos de los ciudadanos que son así dañados. El argumento que pretendía apoyarse en los Derechos humanos, en realidad los desconoce.

3) Pero si consideramos las cosas desde el punto de vista de los países que reciben estos inmigrados nos damos cuenta deque son también los más ricos y los más prósperos, los que proponen los centros de investigación bien equipados y las universidades más prestigiosas, los que se convierten en puntos fuertes de acogida. Promoviendo este así llamado nuevo derecho a la inmigración, estos países defienden su propia prosperidad y reivindican así su permanencia en los puestos de cabeza en el desarrollo científico y económico. Es legítimo que ellos quieran defender sus intereses; pero lo es menos que se quiera travestir esta 
defensa bajo la máscara de la invocación de un nuevo derecho fundamental del hombre. Porque si, como quedó dicho en la objeción segunda, los más pobres corren el riesgo de empobrecerse un poco más, está claro recíprocamente que los más ricos se van a enriquecer un poco más. ¿Esta dialéctica tiene aún algo que ver con la lógica de los Derechos humanos? Aquí, una vez más, bajo la invocación teórica delos derechos, está en juego la concurrencia internacional que toma una nueva dimensión; un soplo de aire que viene de los más poderosos desfavorece a todos aquellos que no tienen los medios para defenderse o de retener con ellos a trabajadores que son, sin embargo, necesarios a la promoción del bien común.

4) Podemos formular, aún, un cuarto argumento. Los países prósperos no defienden sólo su prosperidad, lo que es legítimo. Por el establecimiento de legislaciones que favorecen una llamada de mano de obra o de cerebros altamente cualificados, estos países encuentran una fórmula satisfactoria para rellenar su vacío demográfico. A causa de la escasa renovación de su propia población, estos países van a buscar en otros lugares los recursos humanos que les hacen falta. Dicho de otra forma, compensan así su imprevisión y su despreocupación demográfica a costa de los otros. Borran su inconsciencia pasada, buscan en viveros humanos abundantes, e, incluso en el caso de trabajos poco gratificadores, Ilaman a la población extranjera a ocupar los puestos o funciones que su propia población, demasiado vieja o demasiado delicada, ya no quiere ocupar. Abandonan así tareas ingratas en personas necesitadas que se ven obligadas a salir de su país bajo la presión de la necesidad, y que vienen así a subsanar la inconsciencia de los ricos. Por tanto, ¿se puede fundar la legitimidad de estas prácticas en los Derechos humanos, cuando se trata de compensar políticas de corto alcance y de consagrar la despreocupación demográfica de los países más avanzados? El mismo argumento vale, ya que todos los elementos son, por otra parte, iguales, para la inmigración de los más competentes. Ya me he referido antes a ello. Llamarles desde los países desarrollados es una forma de compensar la propia falta de atención a su devenir demográfico. Esta llamada constituye, pues, una 'recompensa' a su irresponsabilidad...

5) Si nos atenemos a la Europa del año 2001, nos podemos preguntar si a la imprevisión dominante en el pasado reciente, no se añade una inquietante inconsciencia en lo que se refiere al futuro, luego una 
segunda imprevisión. ¿Cuáles serán los efectos previsibles en el equilibrio cultural y político europeo de una llegada eventualmente masiva de poblaciones no europeas? Aquí podemos hacer dos distinciones.

En primer lugar, una parte de los inmigrantes se integrará, sin duda, en la cultura europea, en el supuesto de que se trate de una sola cultura, y ello ocurrirá evidentemente en las capas sociales más educadas. ¿Será esto así para las otras capas? ¿Cómo apreciar los costes humanos de los desarraigos por una partey de la inculturación, si es posible, por otra? ¿Se pueden ignorar estos aspectos? Ciertamente una sociedad moderna presta poca atención a estos desarraigos, como ya había notado Marx a propósito del capitalismo naciente, pero, ¿es necesario mantener la inconsciencia y olvidar los aspectos humanos de este así llamado nuevo derecho, costoso para aquellos que serán sus beneficiarios, a no ser que sean sus víctimas?

Un segundo aspecto del problema es el siguiente: suponiendo que se realice esa integración, aunque no sepamos al final de cuánto tiempo ni bajo qué formas, ¿qué Europa nacerá de esto? También ahora podemos desatender la cuestión, y en nombre de razones económicas minimizar la importancia de los factores culturales y de los equilibrios en la sociedad, como se hace generalmente. Pero un descuido de ese tipo, ¿no sería culpable? Podemos opinar que la objeción no es ciertamente decisiva, que está muy vinculada a miedos hacia el extranjero sin fundamento, que puede reavivarse la xenofobia. Ahora bien, una sospecha legítima no debe, sin embargo, impresionarnos hasta tal punto que se llegue a cegarnos y a despreocuparnos de tomar en cuenta todas las dimensiones de los problemas. Si la llamada a la inmigración se hace en nombre de los intereses rectamente entendidos de Europa, forma parte de esos mismos intereses preguntarse también qué futuro es el que se prepara con ello. ¿Qué Europa? ¿Qué cultura? ¿Qué forma de vivir juntos? A no ser que supongamos que sólo cuentan los intereses económicos, la objeción no debe ser menospreciada. Podría ocurrir que un entusiasmo ingenuo, fundado en necesidades o en consideraciones económicas inmediatas, sea más destructor que fecundo para Europa en cuyo nombre se evocará, sin embargo, este nuevo derecho.

Estas objeciones no son cerradas. Cada una de entre ellas puede y debe ser criticada, medida y apreciada en su justo valor. Cada una no tiene evidentemente el mismo peso. Mi observación principal es la siguiente: no hace falta ocultar intereses estrictamente económicos, o bien ambiciones de dominación, bajo la máscara de los Derechos humanos. Si los países desarrollados 
tienen necesidad de mano de obra en todos los niveles, que lo digan, pero que en ese caso no hablen de Derechos humanos. Se trataría de una impostura, y se pondría en peligro lo que nuestras sociedades democráticas tienen finalmente de más valor, precisamente ese recurso a los Derechos humanos. Es necesario evitar su manipulación y su explotación para fines que les son contrarios. En realidad, independientemente de las posibles auto-justificaciones, es importante interrogarse: ¿no estamos nuevamente ante una ola de aceleración de las desigualdades entre ricos y pobres en el mundo? ¿Podemos razonable y conscientemente desear una perspectiva así? ¿Es necesario que la economía imponga su ley, obligando a desplazamientos de personas y a migraciones con graves consecuencias humanas? Si el economista tiene una palabra que decir, no impidamos que otros puntos de vista se expresen y manifiesten sus preocupaciones. 